\title{
TEMPO E CONDIÇÃO DE ARMAZENAMENTO DAS SEMENTES NA GERMINAÇÃO E DESENVOLVIMENTO DE Passiflora ligularis Juss
}

Andréa Dantas de Souza*

Elisa Mitsuko Aoyama**

Marcos Roberto Furlan***

RESUMO: Passiflora ligularis Juss. é considerada apropriada ao consumo, tendo em vista, por exemplo, seus usos in natura, para sucos e sorvetes, mas não se conhecem pesquisas que obtiveram sucessos sobre o seu desenvolvimento e adaptação em território brasileiro. O custo alto da granadilla para o consumidor, aliado à dificuldade de ser adquirida, inclusive nos supermercados, justificam estudos com o objetivo de verificar a adaptabilidade desta espécie em algumas regiões do Brasil, com potencial produtivo. No presente ensaio, como contribuição às pesquisas sobre o comportamento da granadilla no Brasil, objetivou-se obter informações sobre o efeito do tempo e da condição de armazenamento na germinação das sementes e no desenvolvimento inicial das mudas. As sementes de granadilla foram obtidas de frutos provenientes da Colômbia. O ensaio constou da avaliação da qualidade das sementes com três diferentes períodos de armazenamento, obtendo-se o índice de velocidade de emergência (IVE); porcentagem de germinação e desenvolvimento das mudas. Os tratamentos foram: tratamento A - sementes armazenadas há 24 meses; tratamento $\mathrm{B}$ - sementes armazenadas há 3 meses; e tratamento $\mathrm{C}$ - sementes sem armazenamento. Utilizou-se o delineamento inteiramente casualizado com quatro repetições de 50 sementes, aplicando-se o teste Tukey a 1\% de probabilidade. A obtenção de mudas deve ser feita a partir de sementes mantidas em câmara fria, por período superior a 101 dias. Sementes recém-retiradas de frutos possuem baixa porcentagem de germinação e menor crescimento em altura quando comparadas com plantas provenientes das sementes armazenadas por 24 meses.

PALAVRAS-CHAVE: Fruticultura; Granadilla; Passifloraceae.

\footnotetext{
"Doutoranda em Sanidade, Segurança Alimentar e Ambiental no Agronegócio pelo Instituto Biológico (IB), Brasil; Laboratório de Fitossanidade, Faculdade Integral Cantareira, São Paulo (SP), Brasil.

${ }^{* *}$ Departamento de Ciências Agrárias e Biológicas do Centro Universitário Norte do Espírito Santo (CEUNES); Docente Adjunto I da Universidade Federal do Espírito Santo, Brasil; E-mail: elisaoyama@yahoo.com.br

${ }^{* * *}$ Doutorado em Agronomia (Horticultura) pela Universidade Estadual Paulista Júlio de Mesquita Filho (UNESP), Brasil
} 


\title{
STORAGE TIME AND CONDITIONS OF SEEDS IN GERMINATION AND DEVELOPMENT OF Passiflora ligularis Juss
}

\begin{abstract}
Passiflora ligularis Juss. is highly consumed by people, especially in natura, as juice and ice-cream. However, no successful research is extant on its development and adaptation in Brazil. The high costs of granadilla and the difficulty to buy it, even in supermarkets, justify analysis to verify the adaptability of the species, with production potential, at least in some regions of the country. Current assay is a contribution for research on the behavior of granadilla in Brazil so that information on the effect of time and storage conditions may be obtained for seed germination and the early development stages of the seedlings. Granadilla seeds came from Colombian fruit and the assay focused on the evaluation of seed quality with three different storage periods, with emergence velocity index (EVI) and percentage of seedlings' germination and development. Treatments comprised Treatment A seeds stored for 24 months; Treatment B - seeds stored for 3 months; Treatment $\mathrm{C}$ - seeds without storage. Randomized design with four replications of 50 seeds was employed and comparisons made by Tukey's test at $1 \%$ probability. Seedlings should be obtained from seeds kept in cold chambers for a period of more than 101 days. Seeds which had been only recently removed from the fruit have low germination percentage and small height growth when compared with plants from seeds stored for 24 months
\end{abstract}

KEY WORDS: Fruit Culture; Granadilla; Passifloraceae.

\section{INTRODUÇÃO}

A fruticultura tem se destacado no Brasil, contribuindo positivamente para o crescimento econômico de muitos estados. Acrescentado o fato de que o consumo in natura de frutas e de sucos naturais vem sendo disseminado mundialmente, o que provoca maior estímulo para pesquisadores, produtores e governos. Além da importância econômica, é inquestionável a contribuição na área social, ao estimular a contratação de mão de obra no campo, auxiliando na diminuição do êxodo rural e também do desemprego.

Entre as frutíferas, destaca-se a família Passifloraceae, que apresenta 18 gêneros e aproximadamente 630 espécies distribuídas nas regiões tropicais e subtro- 
picais (HOLM-NEILSEN et al., 1988). Nas Américas o gênero Passiflora é o mais significativo economicamente e composto por 530 espécies (ULMER; MACDOULGAL, 2004). Apesar de muitas possuírem interesse como alimento e ou como medicamento, apenas a Passiflora edulis Sims (maracujá-roxo) e a Passiflora edulis Sims f. flavicarpa Deg (maracujá-amarelo) se destacam na produção mundial.

Essas duas espécies representam 95\% dos cultivos comerciais em todo o mundo, acrescentando que o maracujá-roxo é mais cultivado na Austrália, Sri Lanka, Índia, Nova Zelândia e África do Sul, e o maracujá-amarelo no Brasil, Colômbia, Equador, Venezuela, Austrália, Havaí e Ilhas Fiji (SILVA, 2002).

Em nosso país, atualmente, somente o maracujá-amarelo, destinado principalmente à indústria de suco concentrado, e o Passiflora alata Dryand (maracujádoce), podem ser considerados de importância econômica e por isto recebem maior atenção da pesquisa relacionada aos aspectos agronômicos. Além disto, 95\% dos pomares comerciais brasileiros são constituídos de maracujá-amarelo (RUGGIERO et al., 1996), o que demonstra a escassez de aproveitamento das outras espécies de Passiflora.

No mercado nacional, encontram-se outras passifloráceas, que são obtidas através de importação como, por exemplo, a Passiflora ligularis Juss. (granadilla) e a Passiflora mollissima (HBK) Bailey (curuba).

Apesar de o Brasil ser considerado centro de origem de diversas espécies de Passiflora são raras as pesquisas sobre os aspectos agronômicos das passifloráceas, com exceção das duas produzidas comercialmente.

$\mathrm{O}$ custo alto da granadilla e da curuba para o consumidor, aliado à dificuldade de serem adquiridas, inclusive nos supermercados, justificam estudos com o objetivo de verificar a adaptabilidade destas espécies em algumas regiões do Brasil, com potencial produtivo.

$P$. ligularis Juss. é considerada apropriada ao consumo, tendo em vista, por exemplo, seus usos in natura, para sucos e sorvetes, mas não se conhecem pesquisas que obtiveram sucessos sobre o seu desenvolvimento e adaptação em território brasileiro. A exigência de altitudes superiores a $700 \mathrm{~m}$, conforme alguns autores, aliada à susceptibilidade a geada, restringe a possibilidade de seu cultivo em território nacional. 
A granadilla, além de propagar-se, principalmente, por sementes e ser alógama, ainda não pode ser considerada domesticada pelo ser humano, proporcionando uma variabilidade genética a ser explorada. Apesar do fato de ser vista em alguns países como a principal Passifloraceae, há carência de informações sobre como deve ser a sua condução no campo.

Salazar (2000) e Romero (2000) citam que as porcentagens de germinação são variáveis, desde menores que $20 \%$ até $72,2 \%$.

A falta de unificação da informação contribui para que não exista um pacote tecnológico da produção de material vegetal. Atualmente, na Colômbia, agricultores e viveiristas adotam metodologias convencionais que, na maioria das vezes, repercutem em baixa qualidade de mudas, afetando o desenvolvimento dos cultivos.

No presente ensaio, como contribuição às pesquisas sobre o comportamento da granadilla no Brasil, objetivou-se obter informações sobre o efeito do tempo e da condição de armazenamento na germinação das sementes e no desenvolvimento inicial das mudas.

\section{MATERIAL E MÉTODOS}

O presente trabalho foi realizado na Fazenda Experimental da Faculdade Integral Cantareira, localizada na Serra da Cantareira, Mairiporã, São Paulo. O local está situado a 2319'12" de latitude Sul e 46035'18' de longitude W.G. A área de plantio é caracterizada por Latossolo Vermelho Amarelo Fase Rasa.

O clima, de acordo com a classificação de Köppen, é do tipo Cwb, ou seja, subtropical de altitude com inverno seco e verão ameno, onde a temperatura média do mês mais quente é inferior a $22^{\circ} \mathrm{C}$. A altitude é de $1200 \mathrm{~m}$; precipitação pluviométrica anual média de $1300 \mathrm{a} 1500 \mathrm{~mm}$; temperatura média anual de $20 \mathrm{a} 21^{\circ} \mathrm{C}$; no fundo dos vales é de 18 a $19^{\circ} \mathrm{C}$ na Serra da Cantareira.

As sementes de granadilla foram obtidas de frutos provenientes da Colômbia, e adquiridos de comércio popular, com a coloração amarela, indicando estágio de maturação completa.

O ensaio constou da avaliação da qualidade das sementes com três diferentes períodos de armazenamento, obtendo-se o índice de velocidade de emergência, 
utilizando a equação (IVE $=\mathrm{N} 1 / \mathrm{d} 1+\mathrm{N} 2 / \mathrm{D} 2+\mathrm{Nn} / \mathrm{Dn}$ ), sugerida por Popinigis (1985), onde: N1 é o número de plântulas emergidas no primeiro dia; Nn, número acumulado de plântulas emergidas; D1, primeiro dia de contagem; e Dn, número de dias contados após a semeadura. Calculou-se também a porcentagem de germinação de acordo com Nakagawa (1994) e medida a altura das mudas.

Os tratamentos corresponderam ao tempo de armazenamento das sementes retiradas dos frutos maduros, e foram os seguintes: tratamento $\mathrm{A}-$ sementes armazenadas há 24 meses; tratamento $\mathrm{B}$ - sementes armazenadas há 3 meses; e tratamento $\mathrm{C}$ - sementes sem armazenamento. Utilizou-se o delineamento inteiramente casualizado com quatro repetições de 50 sementes, aplicando-se o teste Tukey a $1 \%$ de probabilidade.

Imediatamente após a retirada dos frutos, as sementes foram postas para fermentar durante 24 horas, a fim de retirar o arilo e restos de placenta, e em seguida foram rigorosamente lavadas com água corrente e secas à sombra, durante 7 dias. Fez-se o tratamento com fungicida a base de Thiran na dosagem $3 \mathrm{~g} \mathrm{~kg}^{-1}$ de sementes e, finalmente, armazenadas em câmara fria $\left(7 \mathrm{a} 10^{\circ} \mathrm{C}\right)$.

As sementes dos tratamentos $\mathrm{A}, \mathrm{B}$ e $\mathrm{C}$ foram semeadas em recipientes de polietileno, com capacidade de 1 litro, individualmente, a uma profundidade de $1 \mathrm{~cm}$, utilizando-se como substrato partes iguais de areia; esterco bovino curtido e terra de barranco, e mantidas em viveiro com tela de $50 \%$ de sombreamento.

Diariamente foi verificado o número de sementes germinadas e, semanalmente, anotadas as alturas das plantas.

\section{RESULTADOS E DISCUSSÃO}

A observação de Parra (2001), de que as sementes de P. ligularis possuem germinação não uniforme e dormência prolongada, também foi constatada no presente trabalho, já que a maior porcentagem de germinação ocorreu no período compreendido entre o $21^{\circ}$ e $025^{\circ}$ dia. Sementes armazenadas por mais tempo na câmara fria iniciaram a germinação mais rapidamente (Tabela 1 ).

O início da germinação também foi próximo aos indicados por Santos Alavarado et al. (1994), que citaram entre 19 e 25 dias, e Cerdas Araya e Castro Retana (2003), que observaram entre 22 e 30 dias. 
Na Tabela 1 encontram-se as quantidades de sementes germinadas em cada tratamento, considerando a soma das quatro repetições, do $23^{\circ}$ ao $26^{\circ}$ dia, e com a finalidade de demonstrar o período de maior emergência.

Tabela 1. Quantidade de sementes germinadas, do $23^{\circ}$ ao $26^{\circ}$ dia após a semeadura de Passiflora ligularis Juss., submetidas aos seguintes tratamentos: tratamento A - sementes armazenadas há 24 meses; tratamento B - sementes armazenadas há 3 meses; e tratamento C - sementes sem armazenamento

\begin{tabular}{ccccc}
\hline & \multicolumn{4}{c}{ Dia após a semeadura } \\
\hline Tratamentos & $23^{\circ}$ & $24^{\circ}$ & $25^{\circ}$ & $26^{\circ}$ \\
\hline A & 8 & 16 & 28 & 4 \\
B & 0 & 0 & 4 & 0 \\
C & 0 & 0 & 0 & 0 \\
\hline
\end{tabular}

Quanto à porcentagem de germinação, aos 93 dias após a semeadura, constatou-se que as sementes armazenadas durante 24 meses em câmara fria $\left(7 \mathrm{a} 10^{\circ} \mathrm{C}\right)$ apresentaram germinação elevada e diferiram significativamente das sementes armazenadas por 3 meses e das recém colhidas (Figura 1).

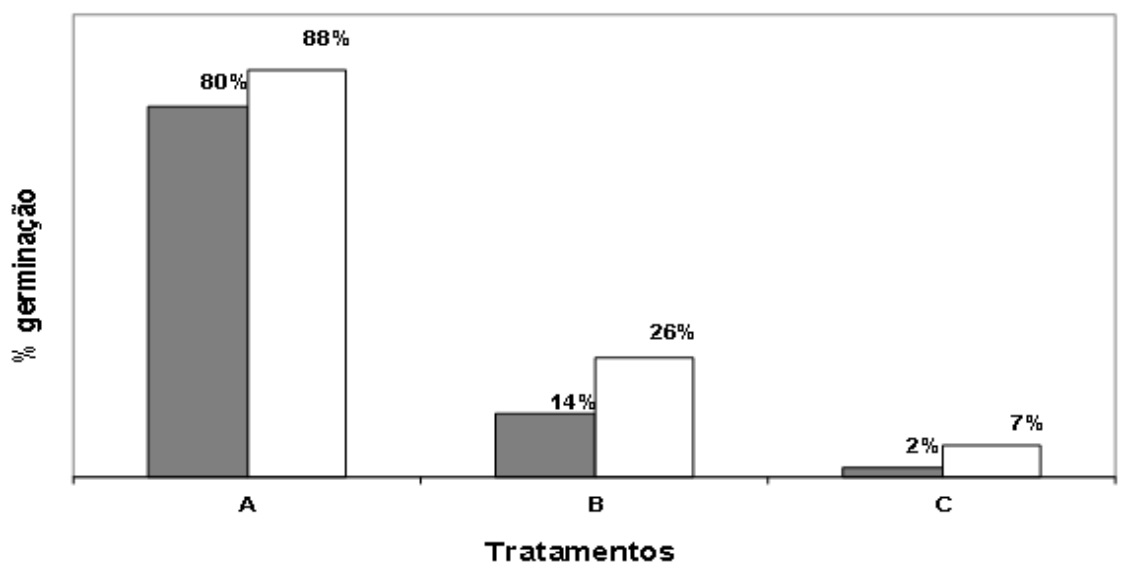

$\square 28$ dias $\square \mathbf{9 3}$ dias

Figura 1. Porcentagem de emergência de plântulas 28 e 93 dias após a semeadura de sementes de Passiflora ligularis Juss., submetidas aos seguintes tratamentos: tratamento A - sementes armazenadas há 24 meses; tratamento B - sementes armazenadas há 3 meses; e tratamento $C$ - sementes sem armazenamento. 
As sementes retiradas de frutos há 13 dias, apesar de receberem o mesmo processo de fermentação e secagem a sombra durante 7 dias, obtiveram a menor taxa de germinação, diferindo significativamente dos demais tratamentos. Através deste resultado também se pode inferir sobre a necessidade de um período para ocorrer a superação de dormência. Resultado semelhante, mas com maracujá-amarelo, foi encontrado por Almeida et al. (1988), que verificaram melhoria na germinação quando as sementes foram armazenadas por período de 6 meses.

Santos Alvarado et al. (1994) conseguiram elevada germinação de sementes de granadilla, quando estas foram previamente estratificadas por 200 horas a $5^{\circ} \mathrm{C}$.

De acordo com metodologia descrita por Popinigis (1985) e Nakagawa (1994), obteve-se também a germinação dessas sementes 28 dias após a semeadura, sendo que as sementes retiradas 24 meses antes obtiveram maior porcentagem de germinação e a diferença foi significativa com relação aos outros dois tratamentos, e as retiradas de frutos 3 meses antes do plantio, obtiveram menor porcentagem de germinação entre os tratamentos, conforme se verifica na Figura 1.

Observou-se pelos resultados, que o lote relacionado ao tratamento A apresentou-se mais vigoroso. No entanto, a procedência das sementes, bem como o efeito do armazenamento, pode ter beneficiado a germinação e o vigor.

Para o cálculo do índice de velocidade de emergência (IVE), foi considerado o período do $23^{\circ}$ ao $30^{\circ}$ dia após a semeadura, pois a partir dessa data os tratamentos com as sementes armazenadas há 3 meses, e as sem armazenamento, obtiveram reduzidas germinações.

Considerando a Tabela 2 pode-se observar que o IVE das sementes armazenadas há 24 meses foi superior aos demais, indicando que as plantas são bem mais vigorosas quando se utiliza sementes armazenadas em câmara fria em temperaturas entre 7 e $10^{\circ} \mathrm{C}$ por 24 meses. No desenvolvimento das mudas utilizou-se como parâmetro a altura média das plântulas do $21^{\circ}$ ao $70^{\circ}$ dia, e os resultados encontram-se na Figura 2 e na Tabela 3. As sementes armazenadas há 24 meses originaram plantas mais vigorosas, chegando a uma altura média de 13,61 cm aos 70 dias após a semeadura. Este valor é inferior ao citado por Cerdas Araya e Castro Retana (2003), que relatam que na Costa Rica, aos 2,5 meses, as plântulas estão entre 15 e $25 \mathrm{~cm}$ de altura. Os tratamentos $\mathrm{B}$ e $\mathrm{C}$ produziram plântulas com altura média de $4,33 \mathrm{~cm}$ 
e 3,75 cm, respectivamente. A menor altura das mudas pode ser devido à época da realização do ensaio, pois semeaduras de maracujazeiros feitas em maio atrasam a emergência e o desenvolvimento, devido à baixa temperatura dos meses seguintes, principalmente no local de execução da semeadura.

Tabela 2. Valores médios de IVE de sementes de Passiflora ligularis Juss., submetidas aos seguintes tratamentos: tratamento A - sementes armazenadas há 24 meses; tratamento B sementes armazenadas há 3 meses; e tratamento $\mathrm{C}$ - sementes sem armazenamento

\begin{tabular}{cc}
\hline Tratamentos & Índice de velocidade de emergência \\
\hline A & $0,8459 \mathrm{a}$ \\
B & $0,2611 \mathrm{~b}$ \\
C & $0,0384 \mathrm{c}$ \\
\hline
\end{tabular}

Médias seguidas da mesma letra não diferem entre si pelo Teste Tukey, a $1 \%$ de probabilidade. Coeficiente de variação $=10,23 \%$.

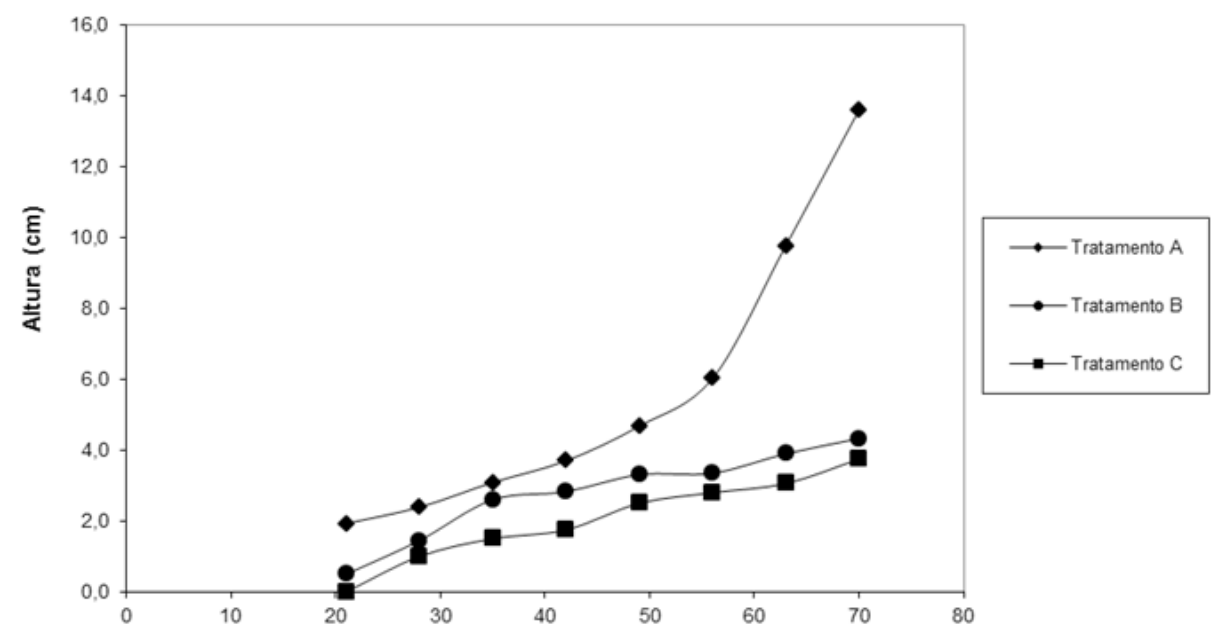

Dias após a semeadura

Figura 2. Média das alturas de plantas de Passiflora ligularis Juss., submetidas aos seguintes tratamentos: tratamento A - sementes armazenadas há 24 meses; tratamento B - sementes armazenadas há 3 meses; e tratamento $\mathrm{C}$ - sementes sem armazenamento. 
Tabela 3. Médias das alturas do $21^{\circ}$ ao $70^{\circ}$ dia após a semeadura das mudas de Passiflora ligularis Juss., submetidas aos seguintes tratamentos: tratamento A - sementes armazenadas há 24 meses; tratamento B - sementes armazenadas há 3 meses; e tratamento $\mathrm{C}$ - sementes sem armazenamento

\begin{tabular}{lccc}
\hline \multicolumn{3}{c}{ Tratamentos } \\
\hline Dias & A & B & C \\
\hline 21 & & Alturas $(\mathbf{c m})$ & \\
28 & 1,93 & 0,50 & 0,00 \\
35 & 2,39 & 1,45 & 1,00 \\
42 & 3,09 & 2,60 & 1,50 \\
49 & 3,70 & 2,83 & 1,75 \\
56 & 4,68 & 3,31 & 2,50 \\
63 & 6,03 & 3,35 & 2,80 \\
70 & 9,78 & 3,90 & 3,06 \\
\hline
\end{tabular}

Através dos dados de altura das plantas, obtiveram-se as equações de regressão da reta (Tabela 4), em que é possível observar que o crescimento diário é superior nas plantas originadas de sementes que foram armazenadas por 24 meses, indicando que as mudas obtidas do lote que sofreu maior período de armazenamento em ambiente refrigerado são mais vigorosas, e as sementes retiradas dos frutos e mantidas apenas por seis dias em baixa temperatura, além de terem baixa germinação como citado anteriormente, também possuem desenvolvimento mais lento.

Tabela 4. Equações da reta e coeficientes de determinação das alturas médias das mudas de Passiflora ligularis Juss., submetidas aos seguintes tratamentos: tratamento A - sementes armazenadas há 24 meses; tratamento B - sementes armazenadas há 3 meses; e tratamento C - sementes sem armazenamento

\begin{tabular}{ccc}
\hline Tratamento & Equações da reta & Coeficiente de determinação \\
\hline A & $\mathrm{y}=0,1791 \mathrm{x}-3,8564$ & 0,8527 \\
$\mathrm{~B}$ & $\mathrm{y}=0,0161 \mathrm{x}-0,2575$ & 0,9635 \\
C & $\mathrm{y}=0,0048 \mathrm{x}-0,1153$ & 0,9611 \\
\hline
\end{tabular}

Enquanto as plantas originadas de sementes armazenadas há 24 meses cresceram em média $0,1791 \mathrm{~cm}$ por dia, as originadas de sementes armazenadas 
há 3 meses, e sem armazenamento, tiveram crescimento diário, respectivamente de 0,0161 e $0,0048 \mathrm{~cm}$ por dia. Os coeficientes de determinação 0,$8527 ; 0,9635 \mathrm{e}$ 0,9611 , respectivamente para os tratamentos A, B e C, indicam alta confiabilidade nas equações da reta.

Os resultados demonstram que a granadilla comporta-se como espécie de clima temperado, por necessitar de frio para sucesso na germinação, conforme observam Metivier (1986) e Bryant (1989).

De qualquer maneira, sugere-se que novos trabalhos devam ser conduzidos, para verificar o período de armazenamento a frio necessário e qual temperatura é ideal.

O comportamento na germinação de sementes de passifloras é variável, como se pode observar nas pesquisas de Kavati e Piza Júnior (2002) com sementes de Passiflora alata, onde concluíram que as mesmas perdem rapidamente o poder germinativo, enquanto que Melo et al. (2000) observaram que sementes de Passiflora nitida necessitam de repouso para germinar, pois as recém-colhidas germinaram menos de $1 \%$, ao passo que as que foram armazenadas após 4 e 8 meses, germinaram 22 e $66 \%$, respectivamente.

\section{CONCLUSÕES}

A obtenção de mudas de granadilla deve ser feita a partir de sementes mantidas em câmara fria, por período superior a 3 meses.

Sementes recém-retiradas de frutos possuem baixa porcentagem de germinação e menor crescimento em altura quando comparadas com plantas provenientes das sementes armazenadas por 24 meses em temperatura de 7 a $10^{\circ} \mathrm{C}$.

\section{REFERÊNCIAS}

ALMEIDA, A. M.; NAKAGAWA, J.; ALMEIDA, R. M. Efeito do armazenamento na germinação de sementes de maracujá-amarelo de diferentes estágios de maturação. Experimento I. In: CONGRESSO BRASILEIRO DE FRUTICULTURA, 9., 1988, Campinas. Anais... Campinas: Sociedade Brasileira de Fruticultura, 1988. p. 603-608. 
BRYANT, J. A. Fisiologia da semente. São Paulo: EPU, 1989. 86p.

CERDAS ARAYA, M. M.; CASTRO RETANA, J. J. Manual práctico para la producción, cosecha y manejo poscosecha del cultivo de granadilla (Passiflora ligularis Juss.). San José: Ministerio de Agricultura y Ganadería de Costa Rica, 2003. 74p.

HOLM-NIELSEN, L. B.; JORGENSEN, P. M.; LAWESSON, J. E. Passifloraceae. In: HARLING; L. Anderson (Ed.). Flora del Ecuador 31, 1988. 124pp.

KAVATI, R.; PIZA JÚNIOR, C. T. A cultura do maracujá-doce. Campinas: CATI, 2002. 46p. (Boletim Técnico, 244).

MELO, A. L.; OLIVEIRA, J. C.; VIEIRA, R. B. Superação de dormência em sementes de Passiflora nitida HBK. com hidróxido de cálcio, ácido sulfúrico e ácido giberélico. Revista Brasileira de Fruticultura, Jaboticabal, v. 22, n. 2, p. 260-263, 2000.

METIVIER, J. R. Citocininas e giberilinas. In: FERRI, M. G. (Ed.) Fisiologia vegetal. 2 ed. São Paulo: EDUSP, 1986. v. 2, p. 93-162,

NAKAGAWA, J. Testes de vigor baseados na avaliação das plântulas. In: VIEIRA, R. D.; CARVALHO, N. M. Testes de vigor em sementes. Jaboticabal: FUNEP, 1994. p. 49-85.

PARRA, A. A. S. Los frutos de dos espécies de Passiflora: Passiflora mollissima (H.B.K.) Bailey y Passiflora ligularis Juss sobre la germinacion de sus semillas. Universitas Scientiarum, v. 6, n. 1, 2001.

POPINIGIS, F. Fisiologia da semente. Brasília: [s.n.], 1985. 289p.

ROMERO, N. P. Evaluación de algunos factores físico y químicos sobre la germinación de las semillas de tres especies de Passiflora: P. edulis, P. mollisima y P. ligularis. Pontificia Universidad Javeriana, 2000.

RUGGIERO, C. et al. Maracujá para exportação: aspectos técnicos da produção. Brasília: Embrapa SPI, 1996. 64p. (Publicações Técnicas FRUPEX, 19). 
SALAZAR, A. A. Evaluación del efecto de la procedencia y el grado de madurez de los frutos de dos especies de passiflora Passiflora mollisima (HBK) Bailey y Passiflora ligularis Juss sobre la germinación de sus semillas. Trabajo de Grado. Pontificia Universidad Javeriana. Facultad de Ciencias. Carrera de Biología. Santa Fe de Bogotá, 2000. 242p.

SANTOS ALVARADO, B.; ALMAGUER VARGAS, G.; BARRIENTOS PRIEGO, A. F. Tratamientos en semillas y evaluación del crecimiento en plantulas de granada china (Passiflora ligularis Juss). Revista Chapingo, Serie Horticultura México, v. 2, n. 1, p. 157-160, 1994.

SILVA, A. A. G. Maracujá amarelo (Passiflora edulis Sims f. flavicarpa Deg.): aspectos relativos à demanda hídrica e conservação pós-colheita. Tese (Tese em Irrigação e Drenagem) - Faculdade de Ciências Agronômicas, Universidade Estadual Paulista, Botucatu, 2002. 98p.

ULMER, T.; MACDOUGAL, J. M. Passiflora: passion-flowers of the World. Timber Press, Inc., 2004. 430p.

Recebido em: 12 de agosto de 2013 Aceito em: 16 de fevereiro de 2014 